\title{
ARTICLE OPEN Efficient screening for COPD using three steps: a cross-sectional study in Mexico City
}

Francisco Franco-Marina ${ }^{1}$, Rosario Fernandez-Plata ${ }^{1}$, Luis Torre-Bouscoulet ${ }^{1}$, Cecilia García-Sancho ${ }^{1}$, Elisa Sanchez-Gallen ${ }^{1}$, David Martinez ${ }^{1}$ and Rogelio Perez-Padilla ${ }^{1}$ for the Study Team

BACKGROUND: Underdiagnosis of chronic obstructive pulmonary disease (COPD) in primary care can be improved by a more efficient screening strategy.

AIMS: To evaluate a three-step method of screening for COPD consisting of an initial short questionnaire followed by measurement of forced expiratory volume in $1 \mathrm{~s} /$ forced expiratory volume in $6 \mathrm{~s}\left(\mathrm{FEV}_{1} / \mathrm{FEV}_{6}\right)$ using an inexpensive pocket spirometer in those with high risk, and diagnostic quality spirometry in those with a low $\mathrm{FEV}_{1} / \mathrm{FEV}_{6}$.

METHODS: We analysed two related Mexico City cross-sectional samples. The 2003 Mexico City PLATINO survey ( $n=542)$ was used to develop a short questionnaire to determine the risk of COPD and a 2010 survey $(n=737)$ additionally used a pocket spirometer. The discriminatory power of the two instruments was assessed with receiver operator characteristic (ROC) curves using three COPD definitions.

RESULTS: The developed COPD scale included two variables from a simple questionnaire and, in ROC analysis, an area under the curve (AUC) between 0.64 and 0.77 was found to detect COPD. The pocket spirometer had an AUC between 0.85 and 0.88 to detect COPD. Using the COPD scale as a first screening step excluded $35-48 \%$ of the total population from further testing at the cost of not detecting $8-18 \%$ of those with COPD. Using the pocket spirometer and sending those with a FEV $/ \mathrm{FEV}_{6}<0.80$ for diagnostic quality spirometry is very efficient, and substantially improved the positive predictive value at the cost of not detecting one-third of COPD cases.

CONCLUSIONS: A three-step screening strategy for COPD substantially reduces the need for spirometry testing when only a COPD scale is used for screening.

npj Primary Care Respiratory Medicine (2014) 24, Article number: 14002; doi:10.1038/npjpcrm.2014.2; published online 20 May 2014

\section{INTRODUCTION}

Chronic obstructive pulmonary disease (COPD) is an underdiagnosed and under-treated condition. ${ }^{1-4}$ One of the main reasons for this is poor access to spirometers. ${ }^{1}$ In the USA, a validated questionnaire (the COPD Population Screener, COPD-PS) with five questions, including respiratory symptoms and risk factors for COPD, has been used to identify patients requiring confirmatory spirometry (http://www.copd.org/screening/survey). While this two-step strategy for COPD detection reduces the proportion of unnecessary spirometry tests, the COPD-PS has only $61 \%$ specificity at the recommended cut-off value ${ }^{5}$ which means that $39 \%$ of those without COPD are sent for diagnostic quality spirometry.

Peak expiratory flow (PEF) can be used to detect severe airflow obstruction, according to data from the population-based multicentre Burden of Obstructive Lung Disease and Proyecto LatinoAmericano de Investigación en Obstrucción Pulmonar (PLATINO) studies. ${ }^{6,7}$ The Burden of Obstructive Lung Disease study investigators found that performing PEF for smokers aged $>40$ and then only sending those with a low PEF for postbronchodilator (BD) spirometry reduced the need for diagnostic quality spirometry to $12 \%$ of the screened population. ${ }^{6}$ However, PEF was obtained with a spirometer whereas more widely available inexpensive mechanical peak flow meters are known to be less accurate and reproducible compared with diagnostic quality spirometers. ${ }^{6,8} \mathrm{~A}$ similar strategy has been tested with other pocket spirometers in selected populations. ${ }^{9,10}$

A 6-second spirometry test has been proposed as a simplified alternative to a more prolonged forced vital capacity (FVC) manoeuvre. $^{11-19}$ Although current criteria to diagnose airflow obstruction and COPD are based on forced expiratory volume in $1 \mathrm{~s}\left(\mathrm{FEV}_{1}\right) / \mathrm{FVC} \mathrm{FEV}_{1} /$ forced expiratory volume in $6 \mathrm{~s}\left(\mathrm{FEV}_{6}\right)$ is almost equivalent, simpler, and possibly more specific. ${ }^{20}$ Several inexpensive electronic devices (also known as pocket spirometers) measure $\mathrm{FEV}_{1}$ and $\mathrm{FEV}_{6}$, an improvement over PEF measurements. ${ }^{21-30}$

Detecting COPD in primary care settings through a three-step strategy consisting of (1) identifying adults with a higher likelihood of having COPD using a questionnaire; (2) performing pocket spirometry; and (3) sending only those positive on pocket spirometry for formal spirometry can be more efficient than only employing a questionnaire or pocket spirometry. We evaluated the performance of this three-step COPD screening strategy in a representative sample of Mexico City residents by determining the proportion of the total population requiring diagnostic quality pre- and post-BD spirometry as well the proportion of undetected COPD cases.

\section{MATERIALS AND METHODS}

Data were obtained from a cross-sectional survey conducted in 2010 in a multi-stage cluster sample of Mexico City residents aged $\geqslant 40$ years. Since

\footnotetext{
${ }^{1}$ Department of Epidemiology, National Institute of Respiratory Diseases, Mexico City, Mexico.

Correspondence: R Perez-Padilla (perezpad@servidor.unam.mx)

Received 30 August 2013; revised 15 December 2013; accepted 14 January 2014
} 
the analysed data did not include all questions used in the COPD-PS, we also present the results of an analysis to develop a COPD scale using a related sample conducted in 2003 as part of the PLATINO study, whose methods have been described in detail elsewhere. ${ }^{31-33}$ The 2010 survey was conducted on the same households as those selected for the PLATINO study and included all residents aged $\geqslant 40$, the majority of whom had also participated in the PLATINO study 7 years earlier. The study protocol for the 2010 survey was approved by our institution's ethics committee, with all participants providing signed informed consent.

Interviewers applied the same structured questionnaire in both surveys (PLATINO, http://www.PLATINO-alat.org). Pre-BD and post-BD spirometry was also performed by trained technicians for each participant at his/her household using portable spirometers of diagnostic quality (EasyOne, NDD Medical Technologies, Zurich, Switzerland) and following the American Thoracic Society quality criteria. ${ }^{34,35}$ All spirometry tests in the PLATINO study were performed using the same model of spirometer. For the 2010 survey we used the EasyOne spirometer connected to a laptop computer (ndd Easy on PC) for $82 \%$ of the study participants. Participants in the 2010 survey also performed three 6-second expiratory manoeuvres with a turbine-based pocket spirometer (COPD-6 model 4000; Vitalograph, Ennis, Ireland). The highest FEV 1 and $\mathrm{FEV}_{6}$ values were independently selected from the three available measurements and used for analysis. To assess the impact of training or fatigue on the measurements, participants were randomly allocated to first perform either the pre-BD diagnostic spirometry test or the pre-BD 6-second spirometry test.

Because of the lack of agreement among experts, three common definitions of COPD were considered: (1) post-BD FEV $1 / F V C<0.70$ (Global Initiative for Chronic Obstructive Lung Disease (GOLD) stages $1-4) i^{36}(2)$ the more specific GOLD stages 2-4 (post-BD FEV $1 / F V C<0.70$ with $\mathrm{FEV}_{1}<80 \%$ predicted); $;^{20,37,38}$ and (3) $\mathrm{FEV}_{1} / \mathrm{FVC}$ below the lower limit of normal (LLN). We used predicted values for $\mathrm{FEV}_{1} / \mathrm{FVC}$ derived from the PLATINO study. ${ }^{30}$

Using the 2003 Mexico City PLATINO dataset as a training sample, we fitted unconditional logistic regression models ${ }^{39}$ to develop a questionnaire-based scale for predicting the log odds of COPD (GOLD stages 1-4) as a function of the following available predictors: age, sex, the presence of cough and phlegm on most days for at least 3 months per year, medical diagnosis of asthma and tuberculosis, pack-years of smoking, and exposure to dust in the workplace and to wood smoke from cooking. Age and pack-years of smoking were initially entered into the logistic model and then the other potential predictors were entered individually to assess whether they had a statistically significant associated coefficient and whether they improved the logistic area under the curve (AUC). Scores for the COPD scale were obtained by multiplying the logistic coefficient associated with each predictor by 10 and rounding off the result to the nearest integer.

Non-parametric receiver operating characteristic (ROC) curves were used to assess the discriminatory power for COPD detection of both the new COPD scale and the raw $\mathrm{FEV}_{1} / \mathrm{FEV}_{6}$ from the pocket spirometer to identify appropriate cut-off values. Additionally, Youden's J statistic, ${ }^{40}$ with equal weights for sensitivity and specificity, was calculated as a measure of test performance. Combined sensitivity and specificity were calculated for a screening strategy consisting of first applying the developed COPD scale and then performing the 6-second spirometry results in those with a COPD scale score indicating COPD. For this strategy, estimates of the proportion of the total screened population requiring confirmatory (diagnostic quality) spirometry and of its combined positive predictive value were obtained for a range of COPD prevalence values using Bayes' theorem.

Agreement between the measurements obtained using the spirometers and the pocket spirometer was assessed with the intraclass correlation coefficient $^{41}$ and the Bland-Altman plot. ${ }^{42}$ All analyses considered the sample design and were performed using STATA software V.12 (StataCorp, College Station, TX, USA).

\section{RESULTS}

The results presented here do not consider either the type of spirometer used or the order in which the 6-second spirometry and diagnostic quality spirometry tests were performed since these two factors had only a marginal influence on our results. The 2003 Mexico City database contained information on 956 participants aged $\geqslant 40$ years with complete information on key variables (Figure 1). Of these, 542 were not included in the 2010 survey and constitute the training sample in which we developed the COPD scale.

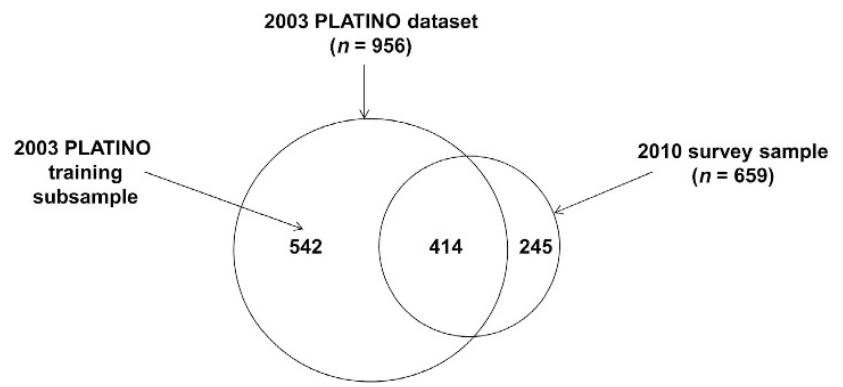

Figure 1. Venn diagram showing the analysed Mexico City samples.

Table 1. Characteristics of participants with post-bronchodilator spirometry in the two analysed samples

\begin{tabular}{|c|c|c|}
\hline & $\begin{array}{c}2003 \text { Mexico City } \\
\text { PLATINO subsample } \\
(n=542)\end{array}$ & $\begin{array}{l}2010 \text { Mexico City } \\
\text { survey sample } \\
(n=659)\end{array}$ \\
\hline \multicolumn{3}{|l|}{ Demographics } \\
\hline \multicolumn{3}{|l|}{ Age group (\%) } \\
\hline $40-49$ & 41.5 & 29.7 \\
\hline $50-59$ & 24.7 & 34.6 \\
\hline $60-69$ & 18.1 & 22.5 \\
\hline $70-79$ & 9.4 & 9.4 \\
\hline$\geqslant 80$ & 6.3 & 3.8 \\
\hline$\%$ Men & 43.9 & 41.1 \\
\hline \multicolumn{3}{|l|}{ Anthropometry, mean (s.d.) } \\
\hline Height $(\mathrm{cm})$ & $156.3(9.5))$ & $156.6(9.1)$ \\
\hline Weight (kg) & $69.5(13.6)$ & $71.6(13.9)$ \\
\hline Body mass index $\left(\mathrm{kg} / \mathrm{m}^{2}\right)$ & $28.4(4.9)$ & $29.2(5.1)$ \\
\hline$\%$ Obese & 29.5 & 37.0 \\
\hline \multicolumn{3}{|l|}{ Respiratory symptoms, \% } \\
\hline $\begin{array}{l}\text { Cough and phlegm on } \\
\text { most days for at least } \\
3 \text { months per year }\end{array}$ & 4.2 & 4.4 \\
\hline $\begin{array}{l}\text { Attack of wheezing with } \\
\text { shortness of breath in the } \\
\text { past } 12 \text { months }\end{array}$ & 3.3 & 2.4 \\
\hline \multicolumn{3}{|l|}{ Medical diagnosis, $\%$} \\
\hline Asthma & 5.0 & 4.9 \\
\hline COPD & 2.4 & 0.8 \\
\hline Tuberculosis & 0.7 & 0.9 \\
\hline \multicolumn{3}{|l|}{ Exposures } \\
\hline \multicolumn{3}{|c|}{ Pack-years of cigarette smoking, \% } \\
\hline Never smoker & 57.2 & 56.2 \\
\hline $1-9$ & 28.0 & 28.7 \\
\hline$\geqslant 10$ & 14.8 & 15.2 \\
\hline $\begin{array}{l}\% \text { who worked in a dusty } \\
\text { job for }>1 \text { year }\end{array}$ & 46.7 & 38.5 \\
\hline $\begin{array}{l}\text { Years exposed to wood } \\
\text { smoke from cooking, } \\
\text { mean (s.d.) }\end{array}$ & $5.5(9.8)$ & $5.2(9.0)$ \\
\hline \multicolumn{3}{|l|}{ COPD prevalence, $\%(\mathrm{n})$} \\
\hline GOLD stages $1-4$ & $9.0(49)$ & $3.6(24)$ \\
\hline GOLD stages $2-4$ & $3.5(19)$ & $1.8(12)$ \\
\hline $\mathrm{FEV}_{1} / \mathrm{FEV}_{6}<\mathrm{LLN}$ & $4.1(22)$ & $2.6(17)$ \\
\hline \multicolumn{3}{|c|}{$\begin{array}{l}\text { Abbreviations: COPD, chronic obstructive pulmonary disease; } \mathrm{FEV}_{1} \text {, forced } \\
\text { expiratory volume in } 1 \mathrm{~s} ; \mathrm{FEV}_{6} \text {, forced expiratory volume in } 6 \mathrm{~s} \text {; GOLD, } \\
\text { Global Initiative for Chronic Obstructive Lung Disease; LLN, lower limit of } \\
\text { normal. }\end{array}$} \\
\hline
\end{tabular}


a

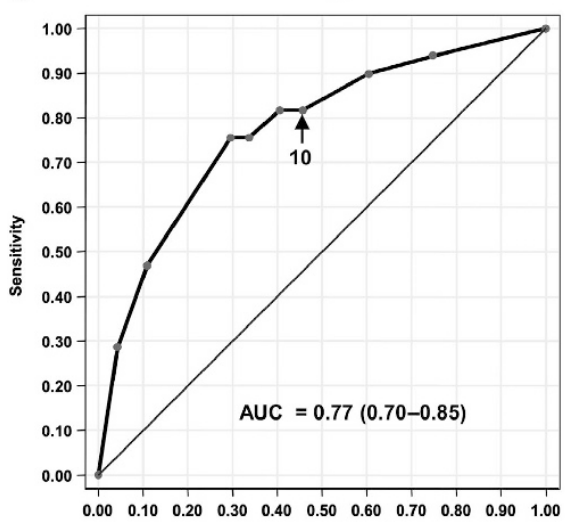

b

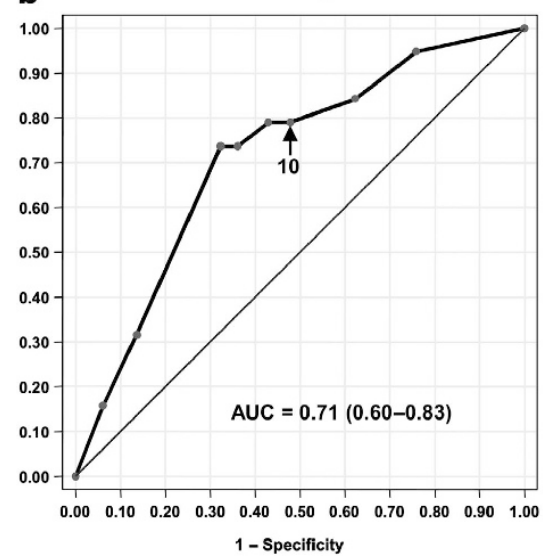

C

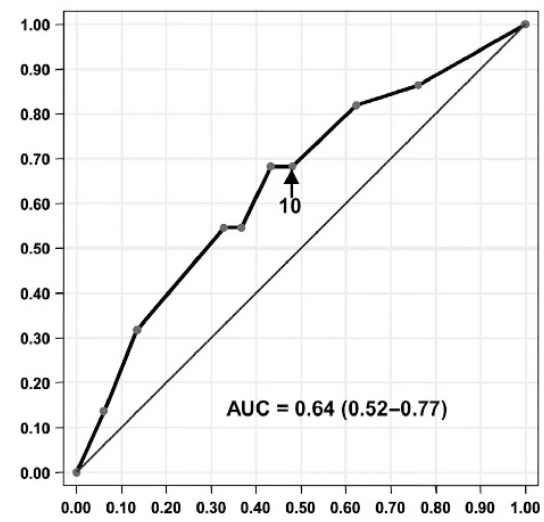

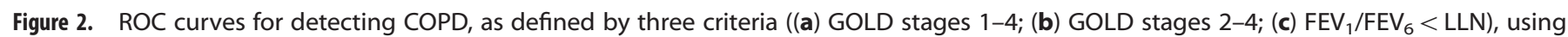
the COPD scale developed from the 2003 Mexico City PLATINO subsample. Numbers close to the curve indicate the selected cut point. Numbers in parenthesis correspond to the $95 \%$ confidence intervals for the area under the curve.

In the 2010 Mexico City survey we identified 1,040 eligible subjects, 737 of whom completed the questionnaires and pre-BD spirometry. Post-BD spirometry with complete questionnaires and 6-second spirometry tests were available for 659 individuals (63.4\% of those eligible), 414 of whom had also participated in the 2003 PLATINO survey. These individuals constitute the sample in which we validated our developed COPD scale.

Summary measures for relevant variables are presented in Table 1 for the two analysed samples. Participants in the 2010 survey were slightly older than those in the 2003 training sample. In both surveys about $40 \%$ of participants were men. The average height was similar in both samples but the average weight and the prevalence of obesity was higher in the 2010 sample. The prevalence of respiratory symptoms, medically diagnosed asthma $(5 \%)$ and tuberculosis $(<1 \%)$ as well as the exposure to tobacco and wood smoke were similar in the two samples. In contrast, participants in the 2010 subsample were less likely to report physician-diagnosed COPD (0.8\%) than those included in the 2003 sample (2.4\%).

Exposure to a dusty job for more than 1 year was less frequently reported in the 2010 subsample than in the 2003 sample (38.5 vs. $46.7 \%)$. The odds of having GOLD stages $1-4$ was 2.6 times lower in the 2010 sample compared with the 2003 sample $(P<0.05$, see Supplementary Table S1). This difference persisted after adjusting for age and pack-years of smoking. Although not statistically significant at $P<0.05$, the odds of having GOLD stages $2-4$ and $\mathrm{FEV}_{1} / \mathrm{FEV}_{6}<\mathrm{LLN}$ were also lower in the 2010 sample (2.0 and 1.6 times lower than in 2003).

Table 2 shows the COPD scale obtained by fitting a logistic regression model to predict COPD GOLD stages 1-4 on the 2003 training database. As expected, COPD prevalence, so defined, increased as age and pack-years of cigarette smoking increased. None of the other variables shown in Table 1 added more information to the prediction (see Supplementary Table S2). The total COPD scale score ranged between 0 and 34 .

The developed COPD scale had an acceptable performance for predicting GOLD stages $1-4$ as assessed by the area under the ROC curve (0.77) (Figure 2). The scale shows lower areas under the curve for predicting GOLD stages 2-4 and COPD defined as FEV $\mathrm{FV}_{1} /$ FEV $_{6}<$ LLN (0.71 and 0.64, respectively). Nevertheless, at the chosen cut-off score of 10 or more, the developed COPD scale was able to identify correctly $82 \%$ of cases with GOLD stages $1-4,79 \%$ of those meeting the GOLD definition for stages $2-4$, and $68 \%$
Table 2. Logistic regression model ${ }^{\mathrm{a}}$ to predict the presence of GOLD stages 1-4 as a function of age and pack-years of smoking in the 2003 Mexico City PLATINO Study subsample $(n=542)$

\begin{tabular}{lccc}
\hline & $\begin{array}{c}\text { Logistic regression } \\
\text { coefficient }\end{array}$ & $\begin{array}{c}\text { Odds ratio } \\
(95 \% \mathrm{Cl})\end{array}$ & $\begin{array}{c}\text { COPD scale } \\
\text { score }^{\mathrm{b}}\end{array}$ \\
\hline $\begin{array}{l}\text { Age group } \\
\text { c }\end{array}$ & & 1 & \\
$50-49$ & 0.8715 & $2.4(0.7-7.7)$ & 0 \\
$\geqslant 60$ & $2.3996^{\mathrm{d}}$ & $11.0(4.3-28)$ & 24 \\
& & \\
Pack-years of cigarette smoking & & \\
Never smoker & & 1 & 0 \\
$1-9$ & 0.5262 & $1.7(0.8-3.4)$ & 5 \\
$10+$ & $0.9592^{\mathrm{d}}$ & $2.6(1.3-5.2)$ & 10 \\
\hline
\end{tabular}

Abbreviations: $\mathrm{Cl}$, confidence interval; COPD, chronic obstructive pulmonary disease; GOLD, Global Initiative for Chronic Obstructive Lung Disease. ${ }^{\text {a }} P$ value on Pearson's chi-squared goodness of fit test $=0.875$. Area under the logistic ROC curve $=0.775$.

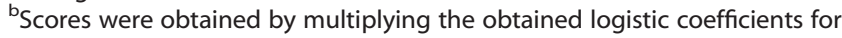
predictors by 10 and rounding off the result to the nearest integer.

${ }^{\mathrm{C}}$ Age computed from date of birth and interview date.

d $P<0.05$ on the corresponding Wald test.

${ }^{\mathrm{e}}$ Never smokers answered 'no' to the following two questions: 'During the past 30 days have you smoked any amount of cigarettes?' and 'Have you ever smoked cigarettes?'. Pack-years in ever smokers were calculated from duration of smoking and average daily cigarette consumption. Average daily cigarette consumption was queried with the following question: 'On the average of the entire time you smoked how many cigarettes did you smoke per day?'. Smoking duration in former smokers was determined by the following questions: 'How old were you when started regular smoking?' and 'How old were you when you stopped smoking?'. In current smokers smoking duration was determined by subtracting the answer given to the question 'How old were you when started regular smoking' from current age.

of those with $\mathrm{FEV}_{1} / \mathrm{FEV}_{6}<\mathrm{LLN}$. On the other hand, the scale specificity ranged from $60 \%$ when the GOLD stages 1-4 definition was employed to $46 \%$ when the $\mathrm{FEV}_{1} / \mathrm{FEV}_{6}<\mathrm{LLN}$ definition was used.

Compared with formal pre-BD spirometry, the pocket spirometer gave similar $\mathrm{FEV}_{1}$ averages in the tested participants of the 2010 survey but lower $\mathrm{FEV}_{6}$ readings (Table 3 ). Consequently, the predicted mean $\mathrm{FEV}_{1} / \mathrm{FEV}_{6}$ in the tested population was higher 
Table 3. Spirometry parameters and variability indicators for pre-BD spirometry and 6-SS test in the Mexico City 2010 survey sample $(n=737)$

\begin{tabular}{|c|c|c|c|}
\hline & $\begin{array}{c}A \\
\text { Spirometry, pre-BD }\end{array}$ & $\begin{array}{c}B \\
\text { COPD-6 6-SS }\end{array}$ & $B-A^{\mathrm{a}}$ \\
\hline Mean (s.d.) FEV $1, \mathrm{~L}$ & $2.46(0.70)$ & $2.44(0.70)$ & -0.02 \\
\hline Mean (s.d.) $\mathrm{FEV}_{1} / \mathrm{FEV}_{6}, \%$ & $80.65(5.53)$ & $85.66(8.08)$ & 5.08 \\
\hline Mean (s.d.) $\mathrm{FEV}_{1}, \%$ predicted & $97.38(16.34)$ & $96.32(15.48)$ & -1.06 \\
\hline Mean (s.d.) $\mathrm{FEV}_{6}, \%$ predicted & $96.61(15.14)$ & $90.52(15.81)$ & -6.24 \\
\hline Mean (s.d.) $\mathrm{FEV}_{1} / \mathrm{FEV}_{6}, \%$ predicted & $100.83(6.79)$ & $107.15(9.78)$ & 6.32 \\
\hline Mean (s.d.) difference between two best $\mathrm{FEV}_{1} / \mathrm{FEV}_{6}$ & $0.01(0.09)$ & $0.02(0.03)$ & 0.01 \\
\hline Mean (s.d.) intratest COV for $\mathrm{FEV}_{1}, \%$ & $2.15(2.49)$ & $5.73(6.37)$ & 3.58 \\
\hline Mean (s.d.) intratest COV for $\mathrm{FEV}_{6}, \%$ & $1.96(2.83)$ & $5.97(6.42)$ & 4.01 \\
\hline Mean (s.d.) intratest COV for $\mathrm{FEV}_{1} / \mathrm{FEV}_{6}, \%$ & $0.86(1.36)$ & $3.51(5.50)$ & 2.65 \\
\hline ATS grade A test quality, $\%$ & $82.63^{b}$ & $71.1^{\mathrm{c}}$ & -11.53 \\
\hline
\end{tabular}

a

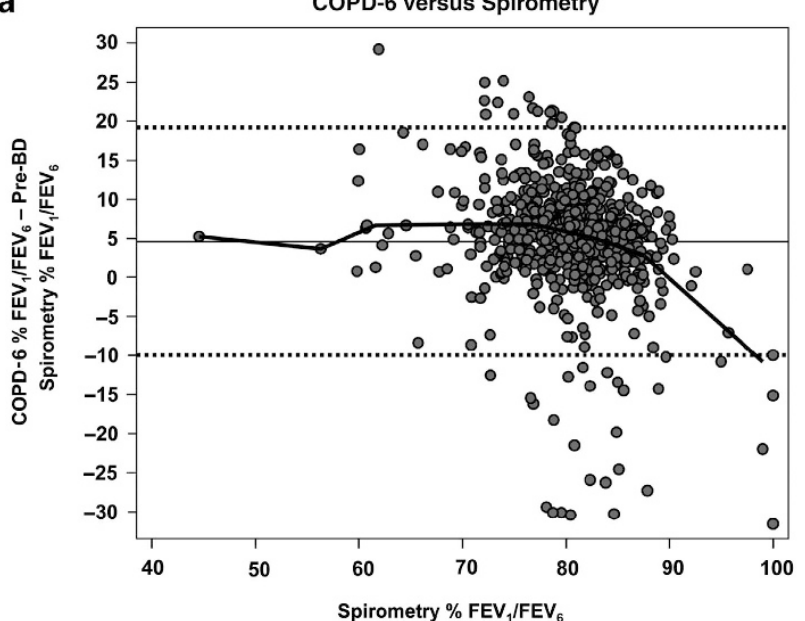

b

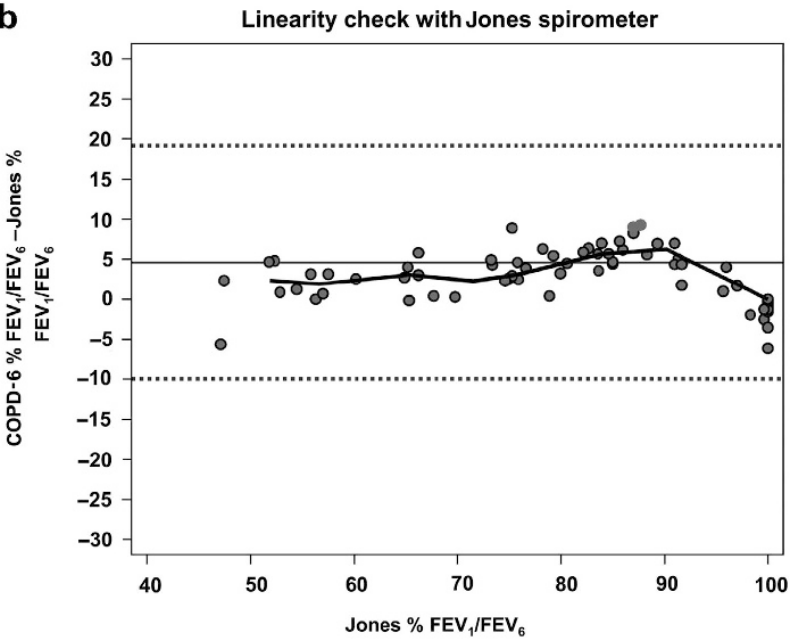

Figure 3. Bland-Altman plot comparing: (a) the $\mathrm{FEV}_{1} / \mathrm{FEV}_{6}$ (\%) obtained from Vitalograph COPD-6 6-SS with that obtained from prebronchodilator spirometry, (b) FEV $1 / \mathrm{FEV}_{6}$ (\%) from COPD-6 with that obtained in the laboratory from the flow-volume calibration syringe. Horizontal dotted lines at about 10 and 20 indicate the limits of agreement of the $\% \mathrm{FEV}_{1} / \mathrm{FEV}_{6}$ difference (within 2 standard deviations of the mean difference). The line over the points corresponds to the median band of the $\% \mathrm{FEV}_{1} / \mathrm{FEV}_{6}$ difference.

when measured by the pocket spirometer (107.1 vs. $100.8 \%$, respectively). The 6-second spirometry test also showed, on average, higher intratest coefficients of variation than those observed in pre-BD spirometry. As a result, only $71 \%$ of the 6 -second spirometry tests had the equivalent of grade A quality compared with approximately $80 \%$ of pre-BD spirometry tests. All these differences were statistically significant at $P<0.05$.

$\mathrm{FEV}_{1} / \mathrm{FEV}_{6}$ values obtained from the pocket spirometer had a poor intraclass correlation: 0.26 comparing 6-second spirometry results with pre-BD spirometry $(95 \%$ confidence interval, $0.19-0.33$, mean difference $+5.1 \%$ ) and 0.34 comparing 6-second spirometry results with post-BD diagnostic spirometry $(95 \%$ confidence interval, $0.27-0.41$, mean difference $+3.7 \%$, see Figure 3). The Bland-Altman plot showed that extreme differences in $\mathrm{FEV}_{1} / \mathrm{FEV}_{6}$ between the two devices (more than twice the s.d.) were frequent (Figure 3). In addition, the pocket spirometer produced lower values for this ratio at values of $90 \%$ and higher. This latter finding was also observed in a laboratory linearity check comparing COPD-6 measurements with a flow-volume calibrator (Flow-Volume Calibrator; Jones Medical Instruments, Oak Brook, IL, USA).

Figure 4 shows the ROC curves for detecting COPD using the pocket spirometer. Not surprisingly, the discriminatory power was better for detecting $\mathrm{FEV}_{1} / \mathrm{FEV}_{6}<\mathrm{LLN}$ (AUC 0.88) than for detecting GOLD stages 1-4 (AUC 0.86) and GOLD stages 2-4 (AUC 0.85).

Table 4 shows sensitivity and specificity estimates at chosen cut-off points obtained using the 2010 dataset. In this sample the COPD scale, positive at a score of $\geqslant 10$, correctly identified $92 \%$ of participants with GOLD stages $1-4$ and $2-4$, and $82 \%$ of those with 
a

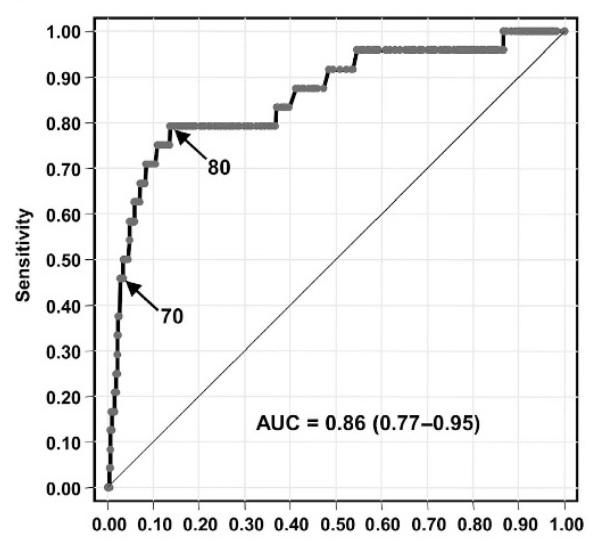

b

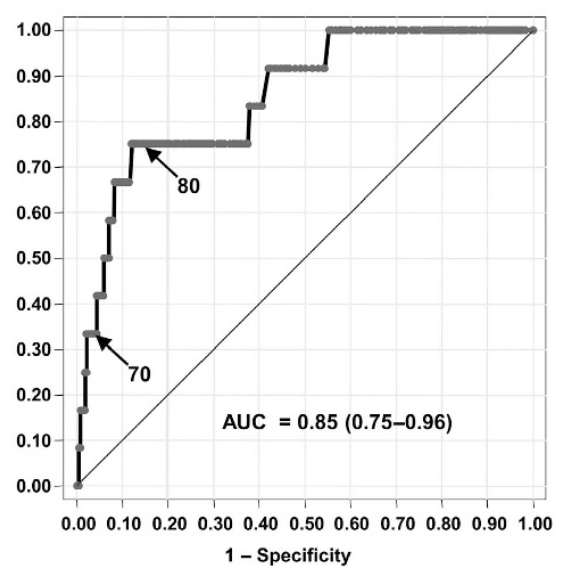

C

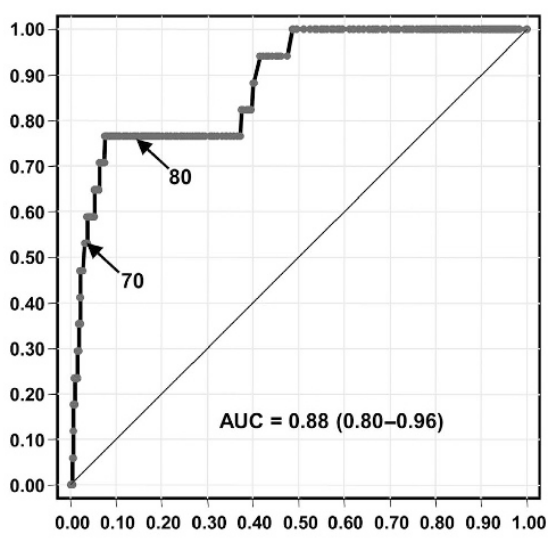

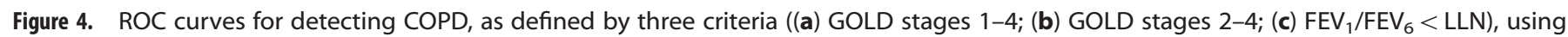
the Vitalograph COPD-6 6-SS in the 2010 Mexico City survey sample. Numbers close to the curve indicate different cut points for the $\mathrm{FEV}_{1} / \mathrm{FEV}_{6} \%$. Numbers in parenthesis correspond to the $95 \%$ confidence intervals for the area under the curve.

$\mathrm{FEV}_{1} / \mathrm{FEV}_{6}<\mathrm{LLN}$. Specificity values of this scale were similar for the three COPD definitions (close to $47 \%$ ).

Youden's J statistic shows that the pocket spirometer-with values ranging between 0.62 and 0.65 depending on the COPD definition used-is a more informative screening test than the COPD scale with values ranging between 0.29 and 0.39 . The pocket spirometer was able to detect almost $80 \%$ of those with GOLD stages $1-4$ and nearly $75 \%$ of those with GOLD stages $2-4$ or with $\mathrm{FEV}_{1} / \mathrm{FEV}_{6}<\mathrm{LLN}$ using a raw $\mathrm{FEV}_{1} / \mathrm{FEV}_{6}<0.80$ to identify those with post-BD airway obstruction.

On the other hand, the specificity of the pocket spirometer would be higher than that found on the COPD scale (close to $85 \%$ for any of the COPD definitions used). If all subjects with a score of $\geqslant 10$ on the COPD scale were tested with the pocket spirometer, two-thirds of the COPD cases (using any COPD definition) would test positive $\left(\mathrm{FEV}_{1} / \mathrm{FEV}_{6}<0.80\right)$. In addition, under this serial testing scenario, the combined specificity would be close to $90 \%$ (also using any COPD definition). Youden's J values for serial testing ranged between 0.53 and 0.60 , not far from those observed for the pocket spirometer alone.

Figure 5 summarises several performance parameters of the serial testing with a range of prevalence values which are similar to those observed for the five Latin American cities included in the PLATINO study. Between 35 and $48 \%$ would not proceed to the second step. If those positive on the COPD scale performed a 6 -second spirometry test, the percentage of the total population requiring all three screening steps including confirmatory spirometry would range from 10 to $20 \%$.

\section{DISCUSSION}

\section{Main findings}

Using logistic regression, we fitted a parsimonious model with only two predictors, age and pack-years of smoking, which are easily obtained. The COPD scale derived from this model had a reasonable accuracy (AUC 0.64-0.77) depending on the COPD definition used.

According to our results in the validation sample, we chose a score of $\geqslant 10$ on the COPD scale as the threshold of COPD risk during the first screening stage, which produced a high sensitivity $(82-92 \%)$ at the cost of a specificity of about $47 \%$. This threshold excludes about half of the population from further screening, missing only $8-18 \%$ of mostly mild COPD cases who would presumably have many years of subsequent screening before developing clinically significant COPD, even if they continued smoking and were susceptible to developing COPD.

The pocket spirometer was found to have higher variability in measuring $\mathrm{FEV}_{1} / \mathrm{FEV}_{6}$ than formal spirometry. This was probably due to the fact that only three expiratory manoeuvres were done, regardless of the repeatability of the results. We also found that the raw $\mathrm{FEV}_{1} / \mathrm{FEV}_{6}$ had better discriminatory power than the percentage predicted $\mathrm{FEV}_{1} / \mathrm{FEV}_{6}$, with areas under the ROC curve 0.02-0.05 higher. Using a cut-off point of $<0.80$, the raw $\mathrm{FEV}_{1} /$ FEV $_{6}$ sensitivity was $75-80 \%$ with a specificity of about $85 \%$.

Combining the COPD scale with pocket spirometry in serial testing enables the detection of two-thirds of COPD cases by performing formal spirometry in a small fraction (10-20\%) of the total screened population. We found that the simplified spirometry by itself had a marginally better test performance than if performed sequentially after a COPD scale. However, acceptance of the simplified spirometry would probably be higher in those found to have an increased likelihood of having COPD by the COPD scale (mainly older smokers), with the additional advantage of reducing the number of pocket spirometry tests needed-an important concern in settings with limited resources.

Interpretation of findings in relation to previously published work Other recently published COPD scales ${ }^{5,43}$ have better sensitivity and specificity than the one we present here. However, our scale can be easily translated into target populations requiring further COPD screening: (1) adults aged $40-49$ years with $\geqslant 10$ pack-years of smoking; (2) ever smokers aged 50-59 years; and (3) all adults aged $\geqslant 60$ years.

In a recent Spanish COPD- 6 validation study ${ }^{44}$ the cut-off point of $<0.80$ for the raw $\mathrm{FEV}_{1} / \mathrm{FEV}_{6}$ was also found to have better sensitivity and specificity than the cut-off point of $<0.70$ recommended by the manufacturer. Using only the percentage predicted $\mathrm{FEV}_{1}$ from the Vitalograph COPD- 6 screening device could have better discriminatory power than the raw $\mathrm{FEV}_{1} / \mathrm{FEV}_{6}$ for detecting cases of severe COPD, but our sample size was too small to exclude random error from this comparison (see Supplementary Figure S1).

The prevalence of COPD or poorly reversible airflow obstruction depends critically on the criteria used..$^{20,37}$ The GOLD stage 1 definition has a high false positive rate in older people. Using GOLD stage 2 (requiring a low $\mathrm{FEV}_{1}$ ) or using $\mathrm{FEV}_{1} / \mathrm{FVC}<\mathrm{LLN}$ provides more specificity. ${ }^{20,36}$ Part of the significant variation in the prevalence of COPD in different cities, which may be higher 


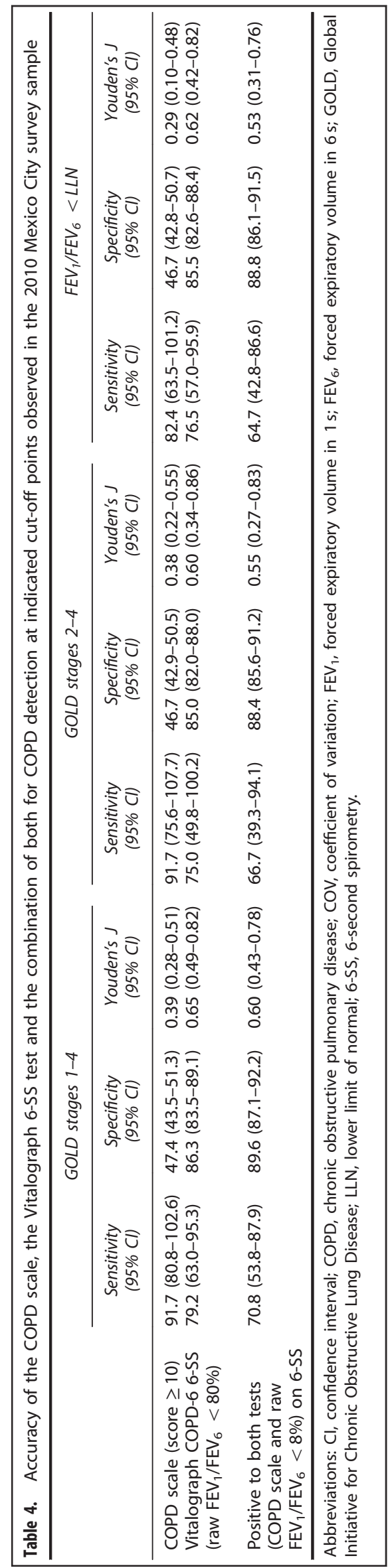

than three-fold based on GOLD stages $1-4$ criteria, $^{45,46}$ may be due to differences in the quality of spirometry tests from one technologist to another. Some technologists urge participants to blow out for many seconds which reduces the measured $\mathrm{FEV}_{1} /$ FVC, thus increasing the estimated prevalence of COPD. ${ }^{47}$ Since the best COPD definition is still a controversial issue, we decided to use three alternative definitions of COPD. Interestingly, our results indicate that the three-step screening strategy was relatively insensitive to the COPD definition employed.

We observed an important reduction in the prevalence of COPD using GOLD 1-4 criteria between the 2010 and 2003 samples and a smaller decrease using GOLD $2-4$ and $\mathrm{FEV}_{1} / \mathrm{FEV}_{6}<\mathrm{LLN}$ criteria, which was not explained by changes in age or pack-years of smoking. Mean forced expiratory time in the 2010 sample was $1.5 \mathrm{~s}$ shorter than in the 2003 sample $(P<0.05)$, which tends to reduce the prevalence of airflow obstruction based on $\mathrm{FEV}_{1} / \mathrm{FVC}$ criteria but not that derived from $\mathrm{FEV}_{1} / \mathrm{FEV}_{6} .{ }^{47}$

\section{Strengths and limitations of this study}

We studied a population sample with an unbiased distribution of risk factors, symptoms, and lung function. Limitations of our study include a relatively small sample size and COPD prevalence (the lowest prevalence in the Burden of Obstructive Lung Disease and PLATINO studies, under any definition). As a consequence, the precision of our estimates of the accuracy of the tested COPD screening instruments may not be optimal, and we could not analyse in detail the performance of the screening instruments by COPD severity. In addition, the results of our population-based study may not apply to patients seen in primary care settings where a higher pre-test prevalence of disease or a higher proportion of persons aged $\geqslant 60$ years is expected.

Implications for future research, policy and practice

No screening strategy is ideal. Diagnostic quality post-BD spirometry, the gold standard for COPD diagnosis, cannot usually be applied to the whole population and is unavailable in primary care, even in developed countries. Minimising the number of these tests should therefore be part of the screening strategy, even at the cost of missing a reasonable proportion of COPD cases, fortunately most of them with mild disease. This can be achieved more efficiently by combining information from a questionnaire and pocket spirometry.

The inclusion in the screening for COPD of a simplified lung function test performed with a low cost pocket spirometer adds objective lung function testing to the screening process, thus helping to solve two important problems in COPD detection: (1) a high rate of false positive diagnoses (up to $50 \%$ of the total population) if only a questionnaire is used for screening; and (2) the identification of a significant proportion of undiagnosed patients with poorly reversible airflow obstruction (COPD or asthma) who are not receiving appropriate treatment. We chose $\mathrm{FEV}_{1} / \mathrm{FEV}_{6}$ over PEF or $\mathrm{FEV}_{1}$ because it is more specific for airway obstruction whereas PEF and $\mathrm{FEV}_{1}$ are also reduced by conditions causing restriction of lung volumes as well as sub-maximal inhalation at the beginning of the forced exhalation. In addition, 6-second spirometry compares volumes $\left(\mathrm{FEV}_{1}\right.$ and $\left.\mathrm{FEV}_{6}\right)$ at fixed times of the expiratory manoeuvre and avoids inconsistencies due to changes in the expiratory time across different centres or over time, an important concern for the generalisability of COPD screening in primary care. Additional information is needed from a clinical study performed in a primary care setting using this threestep screening strategy.

\section{Conclusions}

Our results indicate that screening for COPD is best achieved in terms of yield and cost by a three-step scheme that starts with a 
a

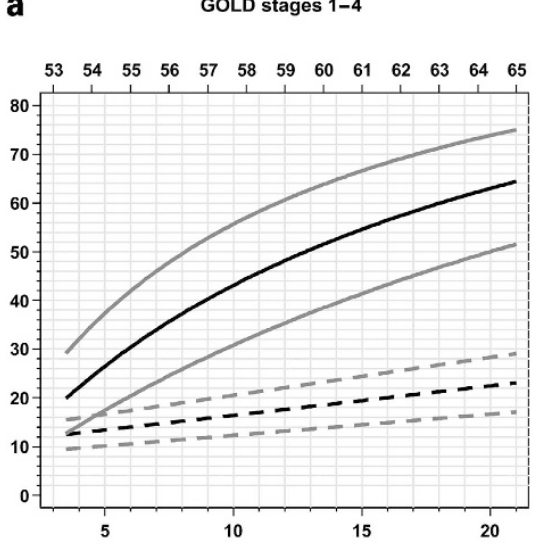

b

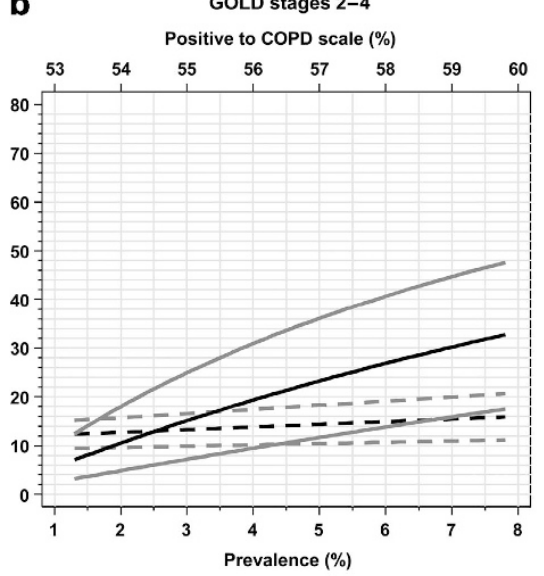

C

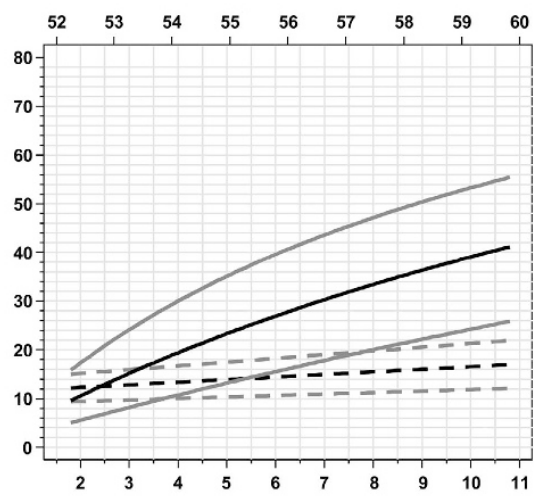

Positive predictive value $\quad-\quad-\%$ of total population requiring confirmatory spirometry

Figure 5. Projected percent of the total population positive to the COPD scale, combined positive predictive value and percent of the total population requiring confirmatory spirometry under serial screening with COPD scale and 6-SS, calculated for a range of COPD prevalence values (with 3 COPD definitions, graph $\mathbf{a}, \mathbf{b}, \mathbf{c}$ ). Grey lines around means correspond to $95 \%$ confidence intervals.

few simple questions, then a pocket spirometry test in those with a higher risk of COPD, therefore restricting spirometry of diagnostic quality only to those with a low $\mathrm{FEV}_{1} / \mathrm{FEV}_{6}$.

\section{ACKNOWLEDGEMENTS}

The Asociación Latinoamericana de Tórax (ALAT) promoted the PLATINO study, Boehringer Ingelheim $\mathrm{GmbH}$ funded the initial 2003 survey including the formulation of the protocol. Boehringer Mexico and CONACYT funded the second survey in Mexico City. The principal investigators of the PLATINO study were Rogelio PerezPadilla for Mexico City, Maria Victorina Lopez-Varela and Adriana Muiño for Montevideo, Maria Montes de Oca and Carlos Talamo for Caracas, Jose R Jardim for Sao Paulo, Gonzalo Valdivia and Carmen Lisboa for Santiago, and Ana Maria B Menezes was the general coordinator of the study. The PLATINO team for Mexico City in addition to the main authors included Alexander Corcho-Berdugo, Benjamin Camacho-Gonzalez, and Diana Torres-Ramos.

\section{CONTRIBUTIONS}

RF-P and FF-M were responsible for the sample selection and field work. CG-S developed part of the study forms and was responsible for creation and handling of the database. Training for the technicians was provided by LT-B and ES-G. ES-G was the spirometry supervisor. DM managed the cartographic data and helped in the statistical analysis. RP-P conceived the research idea, is the guarantor, was responsible for spirometry quality control, and wrote the first draft of the document with FF-M. The article was revised and approved by all contributors.

\section{COMPETING INTERESTS}

The authors declare no conflict of interest.

\section{FUNDING}

This study was financed by a grant from the Mexican National Council for Science and Technology (CONACYT SALUD 2009-01-115466) and received additional funding from Boehringer Ingelheim Mexico.

\section{REFERENCES}

1 Talamo C, de Oca MM, Halbert R, Perez-Padilla R, Jardim JR, Muiño A et al. Diagnostic labeling of COPD in five Latin American cities. Chest 2007; 131: 60-67.

2 Takahashi T, Ichinose M, Inoue H, Shirato K, Hattori T, Takishima T. Underdiagnosis and undertreatment of COPD in primary care settings. Respirology 2003; 8: 504-508.
3 Lindberg A, Bjerg A, Ronmark E, Larsson LG, Lundback B. Prevalence and underdiagnosis of COPD by disease severity and the attributable fraction of smoking: report from the Obstructive Lung Disease in Northern Sweden studies. Respir Med 2006; 100: 264-272.

4 Bednarek M, Maciejewski J, Wozniak M, Kuca P, Zielinski J. Prevalence, severity and underdiagnosis of COPD in the primary care setting. Thorax 2008; 63: 402-407.

5 Martinez FJ, Raczek AE, Seifer FD, Conoscenti CS, Curtice TG, D'Eletto T et al. Development and initial validation of a self-scored COPD Population Screener Questionnaire (COPD-PS). COPD 2008; 5: 85-95.

6 Perez-Padilla R, Vollmer WM, Vazquez-Garcia JC, Enright PL, Menezes AM, Buist AS. Can a normal peak expiratory flow exclude severe chronic obstructive pulmonary disease? Int J Tuberc Lung Dis 2009; 13: 387-393.

7 Jithoo A, Enright PL, Burney P, Buist AS, Bateman ED, Tan WC et al. Case-finding options for COPD: results from the Burden of Obstructive Lung Disease Study. Eur Respir J 2013; 41: 548-555.

8 Chan-Yeung M, Carlsten C. Reasonable alternatives to spirometry for diagnosing chronic obstructive pulmonary disease: is the peak flow meter the answer? Int J Tuberc Lung Dis 2009; 13: 279-280.

9 Schirnhofer L, Lamprecht B, Firlei N, Kaiser B, Buist AS, Halbert RJ et al. Using targeted spirometry to reduce non-diagnosed chronic obstructive pulmonary disease. Respiration 2011; 81: 476-482.

10 Nelson SB, Lavange LM, Nie Y, Walsh JW, Enright PL, Martinez FJ et al. Questionnaires and pocket spirometers provide an alternative approach for COPD screening in the general population. Chest 2012; 142: 358-366.

11 Dias RM. Another parameter for identifying obstructive respiratory disorder: FEV1/ FEV6 in focus. J Bras Pneumol 2007; 33: 13-14.

12 Enright PL, Connett JE, Bailey WC. The FEV1/FEV6 predicts lung function decline in adult smokers. Respir Med 2002; 96: 444-449.

13 Jing JY, Huang TC, Cui W, Xu F, Shen HH. Should FEV1/FEV6 replace FEV1/FVC ratio to detect airway obstruction? A metaanalysis. Chest 2009; 135: 991-998.

14 Lamprecht B, Schirnhofer L, Tiefenbacher F, Kaiser B, Buist SA, Studnicka M et al. Six-second spirometry for detection of airway obstruction: a population-based study in Austria. Am J Respir Crit Care Med 2007; 176: 460-464.

15 Melbye $\mathrm{H}$, Medbo A, Crockett A. The FEV1/FEV6 ratio is a good substitute for the FEV1/FVC ratio in the elderly. Prim Care Respir J 2006; 15: 294-298.

16 Rosa FW, Perez-Padilla R, Camelier A, Nascimento OA, Menezes AM, Jardim JR. Efficacy of the FEV1/FEV6 ratio compared to the FEV1/FVC ratio for the diagnosis of airway obstruction in subjects aged 40 years or over. Braz J Med Biol Res 2007; 40: $1615-1621$.

17 Soares AL, Rodrigues SC, Pereira CA. [Airflow limitation in Brazilian Caucasians: FEV1/FEV6 vs. FEV1/FVC]. J Bras Pneumol 2008; 34: 468-472.

18 Sorino C, Sherrill D, Guerra S, Enright P, Pedone C, Augugliaro G et al. Prognostic value of FEV1/FEV6 in elderly people. Clin Physiol Funct Imaging 2011; 31: 101-107.

19 Vandevoorde J, Verbanck S, Schuermans D, Kartounian J, Vincken W. FEV1/FEV6 and FEV6 as an alternative for FEV1/FVC and FVC in the spirometric detection of airway obstruction and restriction. Chest 2005; 127: 1560-1564. 
20 Perez-Padilla R, Hallal PC, Vazquez-Garcia JC, Muiño A, Máquez M, López MV et al. Impact of bronchodilator use on the prevalence of COPD in population-based samples. COPD 2007; 4: 113-120.

21 Kaufmann M, Hartl S, Geyer K, Breyer MK, Burghuber OC. Measuring FEV6 for detecting early airway obstruction in the primary care setting. Quality and utility of the new Piko-6 device. Respiration 2009; 78: 161-167.

22 Wada H, Nakano Y, Nagao T, Osawa M, Yamada H, Sakaguchi C et al. Detection and prevalence of chronic obstructive pulmonary disease in a cardiovascular clinic: evaluation using a hand held FEV1/FEV6 meter and questionnaire. Respirology 2010; 15: 1252-1258.

23 Frith P, Crockett A, Beilby J, Marshall D, Attewell R, Ratnanesan A et al. Simplified COPD screening: validation of the Piko-6 in primary care. Prim Care Respir J 2011, 20: $190-198$

24 Sichletidis L, Spyratos D, Papaioannou M, Chloros D, Tsiotsios A, Tsagaraki V et al. A combination of the IPAG questionnaire and Piko-6 flow meter is a valuable screening tool for COPD in the primary care setting. Prim Care Respir J 2011; 20 184-189.

25 Garcia-Rio F, Pino JM, Dorgham A, Alonso A, Villamor J. Spirometric reference equations for European females and males aged 65-85 yrs. Eur Respir J 2004; 24 397-405.

26 Hankinson JL, Crapo RO, Jensen RL. Spirometric reference values for the 6-s FVC maneuver. Chest 2003; 124: 1805-1811.

27 Hankinson JL, Odencrantz JR, Fedan KB. Spirometric reference values from a sample of the general U.S. population. Am J Respir Crit Care Med 1999; 159: 179-187.

28 Pereira CA, Sato T, Rodrigues SC. New reference values for forced spirometry in white adults in Brazil. J Bras Pneumol 2007; 33: 397-406.

29 Perez-Padilla R, Torre Bouscoulet L, Vazquez-Garcia JC, Muiño A, Márquez M, López MV et al. [Spirometry reference values after inhalation of $200 \mu \mathrm{g}$ of salbutamol]. Arch Bronconeumol 2007; 43: 530-534.

30 Perez-Padilla R, Valdivia G, Muino A, López MV, Márquez MN, Montes de Oca M et al. [spirometric reference values in 5 large Latin American cities for subjects aged 40 years or over]. Arch Bronconeumol 2006; 42: 317-325.

31 Menezes AM, Victora CG, Perez-Padilla R. The PLATINO project: Methodology of a multicenter prevalence survey of chronic obstructive pulmonary disease in major Latin American cities. BMC Med Res Methodol 2004; 4: 15.

32 Perez-Padilla R, Vazquez-Garcia JC, Marquez MN, Menezes AM. Spirometry quality-control strategies in a multinational study of the prevalence of chronic obstructive pulmonary disease. Respir Care 2008; 53: 1019-1026.

33 Perez-Padilla R, Vazquez-Garcia JC, Marquez MN, Jardim JR, Pertuzé J, Lisboa C et al. The long-term stability of portable spirometers used in a multinational study of the prevalence of chronic obstructive pulmonary disease. Respir Care 2006; 51 1167-1171

34 American Thoracic Society. Standardization of spirometry, 1994 update. Am J Respir Crit Care Med 1995; 152: 1107-1136.
35 Miller MR, Hankinson J, Brusasco V, Burgos F, Casaburi R, Coates A et al. Standardisation of spirometry. Eur Respir J 2005; 26: 319-338.

36 Rabe KF, Hurd S, Anzueto A, Barnes PJ, Buist SA, Calverley P et al. Global strategy for the diagnosis, management, and prevention of chronic obstructive pulmonary disease: GOLD executive summary. Am J Respir Crit Care Med 2007; 176: 532-555.

37 Hardie JA, Buist AS, Vollmer WM, Ellingsen I, Bakke PS, Morkve O. Risk of overdiagnosis of COPD in asymptomatic elderly never-smokers. Eur Respir J 2002; 20: 1117-1122.

38 Vollmer WM, Gislason T, Burney P, Enright PL, Gulsvik A, Kocabas A et al. Comparison of spirometry criteria for the diagnosis of COPD: results from the BOLD study. Eur Respir J 2009; 34: 588-597.

39 Hosmer DW, Lemeshow S. Applied Logistic Regression, 2nd edn. Wiley: New York NY, USA, 2000

40 Li DL, Shen F, Yin Y, Peng JX, Chen PY. Weighted Youden index and its twoindependent-sample comparison based on weighted sensitivity and specificity. Chin Med J (Engl) 2013; 126: 1150-1154.

41 Donner A. A review of inference procedures for the intraclass correlation coefficient in the one-way random effects model. Int Stat Rev 1986; 54: 67-82.

42 Bland JM, Altman DG. Statistical methods for assessing agreement between two methods of clinical measurement. Lancet 1986; 1: 307-310.

43 Salameh P, Khayat G, Waked M. Could symptoms and risk factors diagnose COPD? Development of a diagnosis score for COPD. Clin Epidemiol 2012; 4: 247-255.

44 Represas Represas C, Botana Rial M, Leiro Fernández V, González Silva Al del Campo Pérez V, Fernández-Villar A. Assessment of the portable COPD-6 device for detecting obstructive airway diseases. Arch Bronconeumol 2010; 46: 426-432.

45 Buist AS, McBurnie MA, Vollmer WM, Gillespie S, Burney P, Mannino DM et al. International variation in the prevalence of COPD (the BOLD study): a populationbased prevalence study. Lancet 2007; 370: 741-750.

46 Menezes AM, Perez-Padilla R, Jardim JR, Muiño A, Lopez MV, Valdivia G et al. Chronic obstructive pulmonary disease in five Latin American cities (the PLATINO study): a prevalence study. Lancet 2005; 366: 1875-1881.

47 Perez-Padilla R, Wehrmeister FC, Celli BR, Lopez-Varela MV, Montes de Oca M, Muiño A et al. Reliability of FEV1/FEV6 to diagnose airflow obstruction compared with FEV1/FVC: the PLATINO longitudinal study. PLoS One 2013; 8: e67960.

(c) (1) This work is licensed under a Creative Commons Attribution(c) NonCommercial-ShareAlike 4.0 International License. The images or other third party material in this article are included in the article's Creative Commons license, unless indicated otherwise in the credit line; if the material is not included under the Creative Commons license, users will need to obtain permission from the license holder to reproduce the material. To view a copy of this license, visit http:// creativecommons.org/licenses/by-nc-sa/4.0/

Supplementary Information accompanies the paper on the npj Primary Care Respiratory Medicine website (http://www.nature.com/npjpcrm) 